\title{
Formulation and Performance Evaluation of Wood Adhesives Produced with Rice Husk Ash as New Filler
}

\author{
Ohoke Francis Okemini*, Igwebike-Ossi Clementina Dilim \\ Department of Industrial Chemistry, Ebonyi State University, Abakaliki, Ebonyi State, Nigeria
}

Email address:

pfohoke@yahoo.com (Ohoke F. O.), clemdossi@yahoo.com (Igwebike-Ossi C. D.)

To cite this article:

Ohoke Francis Okemini, Igwebike-Ossi Clementina Dilim. Formulation and Performance Evaluation of Wood Adhesives Produced with Rice Husk Ash as New Filler. American Journal of Applied Chemistry. Vol. 3, No. 2, 2015, pp. 33-39. doi: 10.11648/j.ajac.20150302.11

\begin{abstract}
This study investigated the applicability of rice husk ash (RHA) as filler in wood adhesives containing a blend of ethylene acrylic resin, poly vinyl acetate resin and natural rubber solution. Rice husk, obtained from Rice Mill Industries in Abakaliki, Nigeria, was washed, dried and heated to char (carbonized) on a gas stove until there was no emission of fumes. The rice husk char obtained was incinerated under controlled conditions in a muffle furnace at $650^{\circ} \mathrm{C}$ for four (4) hours. The RHA obtained was ground with ceramic mortar and pestle to reduce the particle size, sieved with a standard $63 \mu \mathrm{m}$ sieve and then used as filler in acrylics/PVA/NR wood adhesive. Filler levels in the adhesives were varied from 0 to $16 \%$. The bond strength and thermal resistance of the prepared adhesives were determined and compared with that produced with $\mathrm{CaCO}_{3}$ as well as a popular brand in the Nigerian market, Top Bond, used as reference standard. The result showed that after application, there was a general increase in bond strength with time for both $\mathrm{CaCO}_{3}$ and RHA adhesives. The highest bond strength was obtained at a filler level of $12 \%$ for both fillers. At this level, RHA adhesive had higher bond strength of $170.3 \mathrm{KPa}$ than $\mathrm{CaCO}_{3}$ adhesive which had $167.8 \mathrm{KPa}$. RHA-filled adhesives were found to be more thermally stable than those of $\mathrm{CaCO}_{3}$ and comparable to the reference standard.
\end{abstract}

Keywords: Filler, Rice Husk Ash, Wood Adhesive, Polyvinyl Acetate, Ethylene Acrylics, Natural Rubber

\section{Introduction}

An adhesive is any non-metallic material that is capable of joining bodies together by surface adhesion and internal strength without the structure of the bodies undergoing significant changes [1]. The technology of adhesives and their uses date back several millennia. Practical ways of uniting articles to provide a joint with resistance to an applied stress have been explored and developed to a useful level by entirely empirical methods. These are applied in several instances such as plywood manufacturing, securing cartons and packages, constructing of aircrafts, affixing postage stamps and manufacturing of carpets [2].

For optimum performance, an adhesive before cure should have good wettability, rheology, evaporative properties, flexibility characters and minimum shrinkage during cure [3]. The ability to wet a surface (wettability) is related to the ease with which a liquid spreads on a solid surface and is essential in maximizing coverage and minimizing voids in the bondlines [4]. Cured adhesives should have good bond strength and thermal stability. Properties like thermal and electrical conductivity can be imparted to adhesives when necessary by the incorporation of conductive filler materials. Materials used as adhesives are polymers, which occur either naturally or are synthetic. Some examples in the natural category include cement (inorganic polymer based on silicates), glues, or pastes, waxes, natural resins, gums and asphaltic pitches as hot melt adhesives. Others in the synthetic category are silicone, epoxy, urethane and phenolic resins to mention but a few. These can also be grouped according to the adherends among which is wood adhesive.

The most important relatively non-adhesive additive in an adhesive formulation is the filler. Fillers are generally added in adhesive formulations to provide some of these simultaneous benefits [3]: increase thermal and electrical conductivity, increase thermal stability, reduce coefficient of thermal expansion, reduce shrinkage and stress during cure, improve bond strength, improve flow properties, extend pot life, reduce cost [3][5]. Substances often used as fillers include: silver flake, aluminium nitride, composite clay, zinc 
oxide, carbon black, hydrated alumina, calcium carbonate, fused silica, silicates and boron nitride. Wood fibres, oil palm fibres, pineapple leaf fibres, banana leaf fibres and a host of other plant derived fibres have been reported as adhesive fillers [6 - 9].

Researchers, in their effort to convert wastes to useful materials, have in the recent years been investigating the use of agro wastes (plant and animal by-products) as filler materials in both thermoplastic and adhesive composites. Several reports have been made on the improvement of the rheology, the adhesion and mechanical properties of adhesives via the incorporation of agro wastes as filler materials [10 - 14]. Rice husk is generated in large quantities in the rice producing areas of the world during the process of rice milling. The domestic and industrial demand for rice husk is extremely low, thus the large volumes of unutilized rice husk in these areas constitute an environmental nuisance [15]. Therefore the use of rice husk ash for industrial application will go a long way in minimizing the accumulation of rice husk in the environment.

Filler applications of rice husk ash (RHA) in plastics, elastomers and other polymer composites have been reported. RHA has been reported as excellent filler in natural rubber and epoxidized natural rubber [16 - 18]. Incorporation of RHA in polypropylene composites has been reported to improve the tensile modulus and flexural modulus of polypropylene/ethylene-propylene-diene terpolymer [5], increase the degree of crystallinity of polypropylene by small margin [19], improve the adhesion and phase continuity in the polypropylene composites[20] and enhances thermal stability of epoxy foams[21]. RHA has been reported as adsorbent in water treatment and vegetable oil treatment [22], as an additive to high performance building blocks, concrete and mortar [23], as extender in textured paint [15] and red oxide primer [24] and as a good flatting extender in cellulose matt paint [25].

In this work, the effects of RHA on the bond strength of acrylics/poly(vinyl acetate)/natural rubber wood adhesives were investigated and compared with adhesives formulated using $\mathrm{CaCO}_{3}$ as filler.

\section{Experimentals}

\subsection{Materials}

i. Binder: Polyvinyl acetate (PVA) and ethylene acrylic emulsions were purchased from Joytex Paint and Industrial Chemicals Limited, Enugu; rubber latex was purchased from Rubber Research Institute, Nekede, Imo State, Nigeria.

ii. Rubber Solution: Rubber latex was allowed to coagulate into a white mass. This white mass was shredded and left under the sun for 24 hours to dry. $4 \mathrm{~g}$ of rubber was then dissolved in $100 \mathrm{ml}$ of toluene to form rubber solution.

iii. Commercial Filler: The commercial filler, $\mathrm{CaCO}_{3}$, used in this study was obtained from Glisco Laboratory Chemicals Limited, Enugu, Nigeria.

\subsection{Methods}

\subsubsection{Preparation of Rice Husk Ash Filler}

Rice husk was obtained from a rice mill in Abakaliki, Ebonyi State, Nigeria. The rice husk was first washed severally with clean water to remove stone, sand and dust contaminants. It was again rinsed with distilled water to remove the metal ions that may be contained as impurities in the previous water. The washed rice husk was spread on a stainless tray and broken rice grains present were removed by handpicking. It was then left to dry in a dust free environment.

The dried rice husk was burnt to char using a stainless steel pot. This stage of burning is called carbonization. Carbonized rice husk was weighed in crucibles and fed into a muffle furnace using the same crucibles; the temperature of the furnace was set at $650^{\circ} \mathrm{C}$ and left for 4 hours. After 4 hours, white rice husk ash in a granular form was obtained. The rice husk ash-containing crucibles were removed from the furnace, allowed to cool and weighed again. The rice husk ash was ground in a ceramic mortar and pestle to obtain rice husk ash powder of smaller particle size. The ground ash was sieved with standard sieve of $63 \mu \mathrm{m}$ mesh.

\subsubsection{Compounding of Wood Adhesive}

The following reagents were used for the preparation of wood adhesive: Binder (polyvinyl acetate, acrylics and rubber solution), Filler (Calcium carbonate and Rice husk ash), Curing agent (sulphur), Plasticizer (glycerol), Surfactant (sodium laurylsulphate), Antifoam (paraffin oil) and Preservative (sodium benzoate).

\subsubsection{Mixing Ratio of Components in Wood Adhesive Formulations}

Table 1. Typical formulation used for the production of wood adhesives.

\begin{tabular}{ll}
\hline Ingredient & Wt $\%$ \\
\hline Acrylics/PVA/NR (8:1:1) & 94.50 \\
Surfactant & 1.00 \\
Plasticizer & 1.00 \\
Antifoam & 1.00 \\
Filler & $0.00-16.00$ \\
Curing agent & 1.00 \\
Anti-oxidant & 1.00 \\
Preservative & 0.50 \\
& 100.00 \\
\hline
\end{tabular}

Table 2. Formulation of acrylics/PVA/NR wood adhesive using varied wt $\%$ of $\mathrm{CaCO}_{3}$ filler.

\begin{tabular}{|c|c|c|c|c|c|c|c|c|}
\hline Component & WA0C & WA4C & WA6C & WA8C & WA10C & WA12C & WA14C & WA16C \\
\hline Acrylics/PVA/NR & 94.50 & 90.50 & 88.50 & 86.50 & 84.50 & 82.50 & 80.50 & 78.50 \\
\hline Surfactant & 1.00 & 1.00 & 1.00 & 1.00 & 1.00 & 1.00 & 1.00 & 1.00 \\
\hline Plasticizer & 1.00 & 1.00 & 1.00 & 1.00 & 1.00 & 1.00 & 1.00 & 1.00 \\
\hline Antifoam & 1.00 & 1.00 & 1.00 & 1.00 & 1.00 & 1.00 & 1.00 & 1.00 \\
\hline
\end{tabular}




\begin{tabular}{|c|c|c|c|c|c|c|c|c|}
\hline Component & WA0C & WA4C & WA6C & WA8C & WA10C & WA12C & WA14C & WA16C \\
\hline $\mathrm{CaCO}_{3}$ & 0.00 & 4.00 & 6.00 & 8.00 & 10.00 & 12.00 & 14.00 & 16.00 \\
\hline Curing agent & 1.00 & 1.00 & 1.00 & 1.00 & 1.00 & 1.00 & 1.00 & 1.00 \\
\hline Anti-oxidant & 1.00 & 1.00 & 1.00 & 1.00 & 1.00 & 1.00 & 1.00 & 1.00 \\
\hline \multirow[t]{2}{*}{ Preservative } & 0.50 & 0.50 & 0.50 & 0.50 & 0.50 & 0.50 & 0.50 & 0.50 \\
\hline & 100 & 100 & 100 & 100 & 100 & 100 & 100 & 100 \\
\hline
\end{tabular}

Table 3. Formulation of acrylics/PVA/NR wood adhesive using varied wt $\%$ of RHA filler.

\begin{tabular}{|c|c|c|c|c|c|c|c|c|}
\hline Component & WA0R & WA4R & WA6R & WA8R & WA10R & WA12R & WA14R & WA16R \\
\hline Acrylics/PVA/NR & 94.50 & 90.50 & 88.50 & 86.50 & 84.50 & 82.50 & 80.50 & 78.50 \\
\hline Surfactant & 1.00 & 1.00 & 1.00 & 1.00 & 1.00 & 1.00 & 1.00 & 1.00 \\
\hline Plasticizer & 1.00 & 1.00 & 1.00 & 1.00 & 1.00 & 1.00 & 1.00 & 1.00 \\
\hline Antifoam & 1.00 & 1.00 & 1.00 & 1.00 & 1.00 & 1.00 & 1.00 & 1.00 \\
\hline RHA & 0.00 & 4.00 & 6.00 & 8.00 & 10.00 & 12.00 & 14.00 & 16.00 \\
\hline Curing agent & 1.00 & 1.00 & 1.00 & 1.00 & 1.00 & 1.00 & 1.00 & 1.00 \\
\hline Anti-oxidant & 1.00 & 1.00 & 1.00 & 1.00 & 1.00 & 1.00 & 1.00 & 1.00 \\
\hline \multirow[t]{2}{*}{ Preservative } & 0.50 & 0.50 & 0.50 & 0.50 & 0.50 & 0.50 & 0.50 & 0.50 \\
\hline & 100.00 & 100.00 & 100.00 & 100.00 & 100.00 & 100.00 & 100.00 & 100.00 \\
\hline
\end{tabular}

Key: WA4C $=$ wood adhesive with $4 \%$ of $\mathrm{CaCO}_{3}$; WA4R $=$ wood adhesive with $4 \%$ of $\mathrm{RHA}$

A total of sixteen (16) samples of wood adhesive were produced. The first eight (8) samples (WA-C) was formulated with acrylics/PVA/NR binder and $\mathrm{CaCO}_{3}$ filler while the second eight samples (WA-R) were formulated with acrylics/PVA/NR binder and rice husk ash filler. All the samples were formulated with variations in the filler levels from $0-16 \mathrm{wt} \%$ at the expense of the binder. The ratios of other components were kept constant. The quality parameters of each formulated sample were compared to that of Top Bond, a popular commercial brand of wood adhesive in the Nigerian market.

\subsubsection{Tested Wood Adhesive Quality Parameters}

\section{(i). Bond Strength}

A simple, effective improvised technique [26] was employed. A wood sample was cut to $200 \mathrm{mmx} 45 \mathrm{~mm}$ bonding surface. The adhesive was applied on only a section $(60 \mathrm{~mm} \times 45 \mathrm{~mm})$ of the wood surface leaving $140 \mathrm{mmx} 45 \mathrm{~mm}$ of the bonded wood free on both sides. After the curing process, one end of the bonded wood was firmly attached to the surface of a table by means of a clamp. On the other end of it, standard weights were gradually applied via a loop. The force was gradually increased until at a point when pull-off between the two surfaces was noticed. The value of the force (x) was regarded as the adhesive bond strength expressed in $\mathrm{N} / 27000 \mathrm{~mm}^{2}$ [26].

The value of $\mathrm{x}$ was converted to $\mathrm{Y}$ expressed in Kilopaschals $\left(1000 \mathrm{~N} / \mathrm{m}^{2}\right)$ using the following formula:

$$
\mathrm{Y}=37.04 \mathrm{x}
$$

Where $\mathrm{x}=\frac{N}{27000 \mathrm{~mm}^{2}}($ measured $)$

$$
\mathrm{Y}=1000 \frac{\mathrm{N}}{\mathrm{m}^{2}} \text { (Kilopaschals) }
$$

$37.04=$ constant

\section{(ii). Thermal Stability Determination}

The thermal stability of the adhesive was determined to find out the degree to which its bond strength can withstand temperature variations [3][27]. Two pairs of bonded wood samples were prepared. One pair was kept in an electric oven (DHG9033A) at the temperature of $98-100^{\circ} \mathrm{C}$ for 2 hours while the other pair was kept in a refrigerator $\left(\right.$ at $\left.0-2^{\circ} \mathrm{C}\right)$ for 2 hours. The bond strength of each pair was determined and recorded. The process was repeated for 3 hours and 4 hours inspection intervals. Thermal stability test was conducted on the 16 samples and also on Top Bond.

\section{Results and Discussion}

\subsection{Results}

\subsection{1. pH of Acrylics/PVA/NR Wood Adhesives Filled with Either $\mathrm{CaCO}_{3}$ or $\mathrm{RHA}$}

Table 4. $p H$ of the formulated wood adhesives and TB.

\begin{tabular}{llc}
\hline & \multicolumn{2}{l}{ Acrylics/PVA/NR adhesives } \\
\hline Wt\% of filler & $\mathbf{C a C O}_{3}$ & RHA \\
0 & 6.7 & 6.7 \\
4 & 6.7 & 6.7 \\
6 & 6.7 & 6.7 \\
8 & 6.7 & 6.7 \\
10 & 6.7 & 6.7 \\
12 & 6.7 & 6.7 \\
14 & 6.8 & 6.7 \\
16 & 6.8 & 6.8 \\
TB & 6.6 & 6.6 \\
\hline
\end{tabular}




\subsubsection{Bond Strength of Wood Adhesives}

Table 5. Bond strength (KPa) of $\mathrm{CaCO}_{3}$-filled, RHA-filled acrylic/PVA/NR and TB wood adhesives.

\begin{tabular}{lllllll}
\hline \multirow{2}{*}{$\%$ filler } & $\mathbf{2}$ hours & \multicolumn{3}{c}{$\mathbf{1}$ day } & \multicolumn{3}{l}{ days } \\
\cline { 2 - 7 } & $\mathbf{C a C O}$ & $\mathbf{R H A}$ & $\mathbf{C a C O}_{3}$ & $\mathbf{R H A}$ & $\mathbf{C a C O}_{3}$ & RHA \\
\hline 0 & $93.00 \pm 0.06$ & $93.00 \pm 0.04$ & $140.00 \pm 0.05$ & $140.00 \pm 0.02$ & $165.90 \pm 0.01$ & $165.90 \pm 0.04$ \\
4 & $93.30 \pm 0.04$ & $93.30 \pm 0.04$ & $140.40 \pm 0.06$ & $140.70 \pm 0.03$ & $166.60 \pm 0.01$ & $167.04 \pm 0.04$ \\
6 & $93.40 \pm 0.01$ & $93.80 \pm 0.02$ & $140.40 \pm 0.01$ & $140.70 \pm 0.02$ & $166.60 \pm 0.01$ & $167.04 \pm 0.01$ \\
8 & $93.70 \pm 0.11$ & $94.60 \pm 0.04$ & $140.70 \pm 0.01$ & $141.10 \pm 0.02$ & $167.04 \pm 0.02$ & $167.80 \pm 0.02$ \\
10 & $94.10 \pm 0.06$ & $95.00 \pm 0.04$ & $140.70 \pm 0.03$ & $141.90 \pm 0.04$ & $167.04 \pm 0.05$ & $169.80 \pm 0.01$ \\
12 & $94.40 \pm 0.06$ & $95.80 \pm 0.03$ & $141.10 \pm 0.04$ & $142.20 \pm 0.03$ & $167.80 \pm 0.01$ & $170.30 \pm 0.06$ \\
14 & $94.40 \pm 0.01$ & $95.80 \pm 0.01$ & $141.10 \pm 0.04$ & $142.20 \pm 0.05$ & $167.40 \pm 0.07$ & $169.30 \pm 0.01$ \\
16 & $94.10 \pm 0.02$ & $95.00 \pm 0.02$ & $140.70 \pm 0.10$ & $141.90 \pm 0.01$ & $167.04 \pm 0.03$ & $168.50 \pm 0.02$ \\
TB & $95.80 \pm 0.02$ & $95.80 \pm 0.06$ & $142.60 \pm 0.11$ & $142.60 \pm 0.01$ & $169.60 \pm 0.03$ & $169.60 \pm 0.05$ \\
\hline
\end{tabular}

\subsubsection{Thermal Stability of Wood Adhesives}

Table 6. Bond strength (KPa) of $\mathrm{CaCO}_{3}$-filled and RHA-filled Acrylics/PVA/NR adhesives at room temp, $98-100^{\circ} \mathrm{C}$ and $0-2^{\circ} \mathrm{C}$.

\begin{tabular}{|c|c|c|c|c|c|c|}
\hline \multirow{2}{*}{ Wt $\%$ of filler } & \multicolumn{3}{|c|}{$\mathrm{CaCO}_{3}$-filled Acrylics/PVA adhesives } & \multicolumn{3}{|c|}{ RHA-filled Acrylics/PVA adhesives } \\
\hline & $98-100^{\circ} \mathrm{C}$ & Room temp & $0-2^{\circ} \mathrm{C}$ & $98-100^{\circ} \mathrm{C}$ & Room temp & $0-2^{\circ} \mathrm{C}$ \\
\hline 0 & $162.2 \pm 0.15$ & $165.9 \pm 0.06$ & $140.8 \pm 0.04$ & $162.9 \pm 0.09$ & $167.1 \pm 0.16$ & $154.8 \pm 0.10$ \\
\hline 4 & $162.2 \pm 0.01$ & $166.7 \pm 0.02$ & $140.8 \pm 0.04$ & $163.3 \pm 0.03$ & $167.4 \pm 0.11$ & $155.6 \pm 0.01$ \\
\hline 6 & $163.0 \pm 0.07$ & $166.7 \pm 0.02$ & $141.1 \pm 0.03$ & $164.1 \pm 0.08$ & $168.5 \pm 0.09$ & $155.6 \pm 0.01$ \\
\hline 8 & $163.3 \pm 0.09$ & $167.1 \pm 0.03$ & $141.1 \pm 0.07$ & $164.1 \pm 0.09$ & $168.9 \pm 0.05$ & $156.7 \pm 0.02$ \\
\hline 10 & $164.1 \pm 0.01$ & $167.1 \pm 0.03$ & $142.6 \pm 0.01$ & $165.9 \pm 0.01$ & $169.6 \pm 0.15$ & 157.10 .07 \\
\hline 12 & $164.5 \pm 0.01$ & $167.8 \pm 0.04$ & $142.6 \pm 0.03$ & $165.9 \pm 0.01$ & $170.0 \pm 0.01$ & $157.1 \pm 0.01$ \\
\hline 14 & $163.7 \pm 0.01$ & $167.4 \pm 0.03$ & $143.0 \pm 0.09$ & $165.6 \pm 0.01$ & $169.6 \pm 0.01$ & $157.1 \pm 0.06$ \\
\hline 16 & $163.7 \pm 0.04$ & $167.1 \pm 0.02$ & $142.6 \pm 0.02$ & $165.6 \pm 0.06$ & $169.3 \pm 0.10$ & $1563 \pm 0.03$ \\
\hline TB & $165.9 \pm 0.05$ & $169.6 \pm 0.06$ & $161.4 \pm 0.01$ & $165.9 \pm 0.14$ & $169.6 \pm 0.02$ & $161.4 \pm 0.03$ \\
\hline
\end{tabular}

Graphical illusrtations

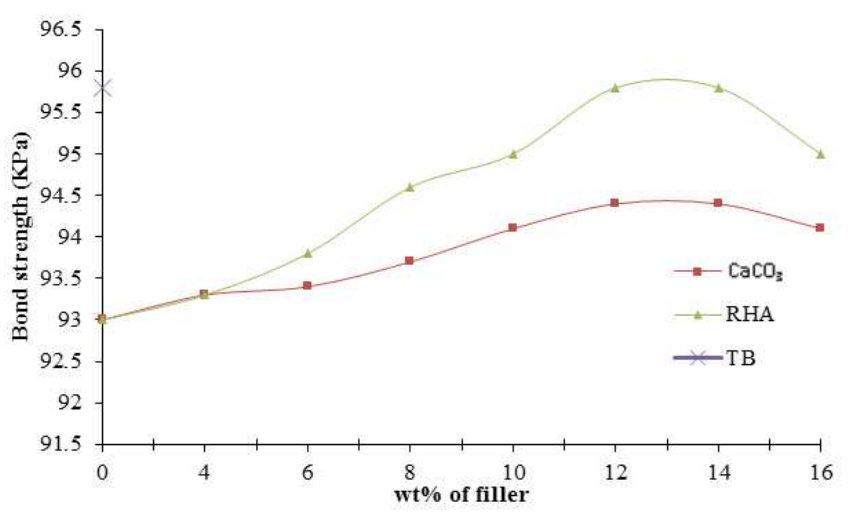

Fig. 1a. Plots of bond strength (KPa) versus wt\% of filler for $\mathrm{CaCO}_{3}$ and RHA filled.

Acrylics/PVA/NR adhesives (2hours after application).

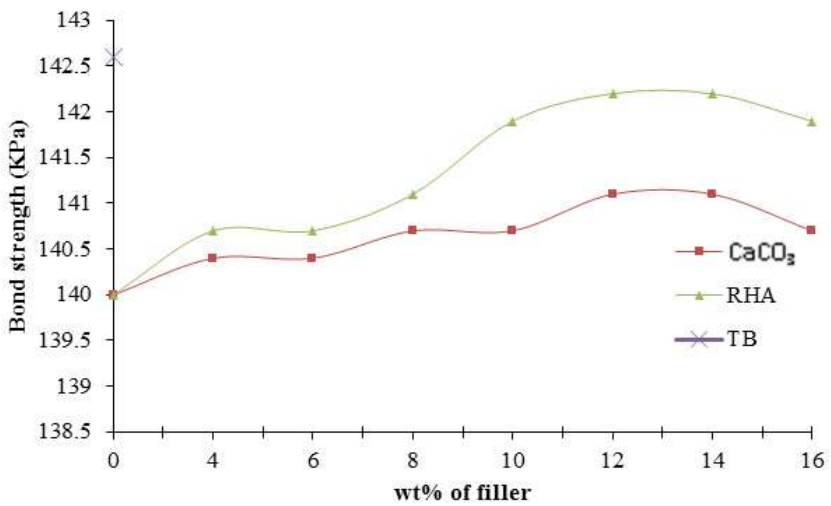

Fig. 1b. Plots of bond strength (KPa) versus wt\% of filler for $\mathrm{CaCO}_{3}$ and RHA filled.

Acrylics/PVA/NR adhesives (1 day after application) 


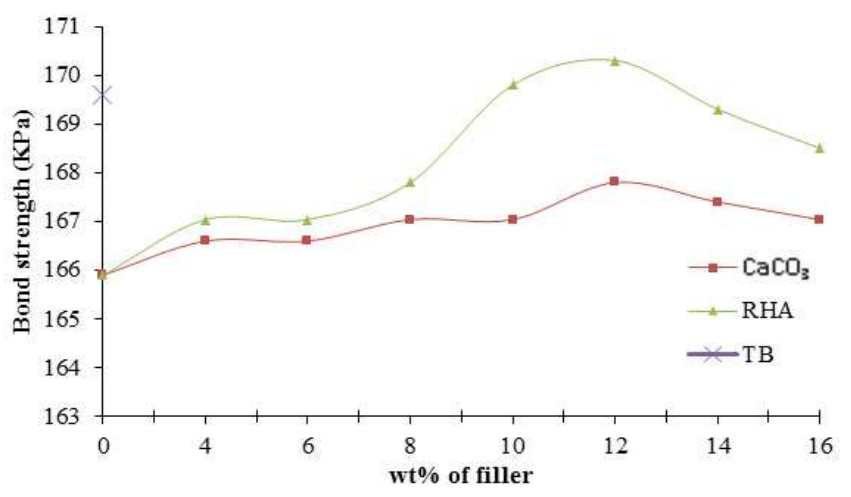

Fig. 1c. Plots of bond strength (KPa) versus wt\% of filler for $\mathrm{CaCO}_{3}$ and RHA filled.

Acrylics/PVA/NR adhesives (7 days after application)

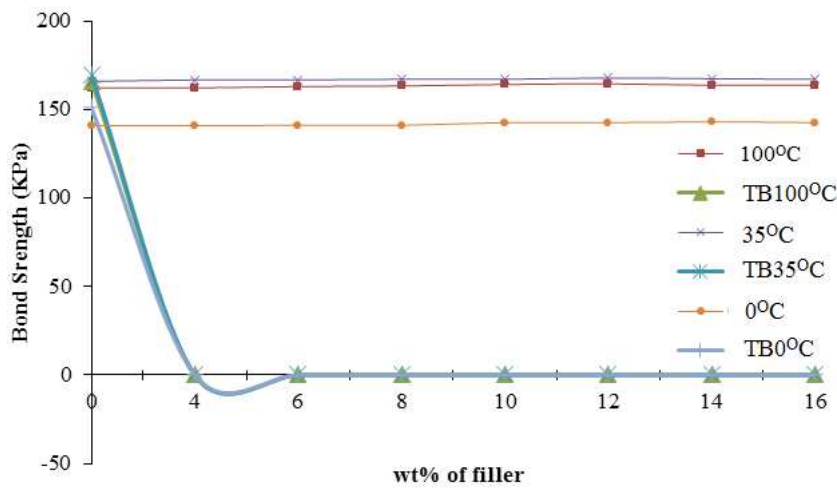

Fig. 2a. Plots of bond strength (KPa) versus wt\% of filler for $\mathrm{CaCO}_{3}$ filled Acrylics/PVA/NR.

adhesives at room temp $\left(35^{\circ} \mathrm{C}\right), 100^{\circ} \mathrm{C}$ and $0^{\circ} \mathrm{C}$

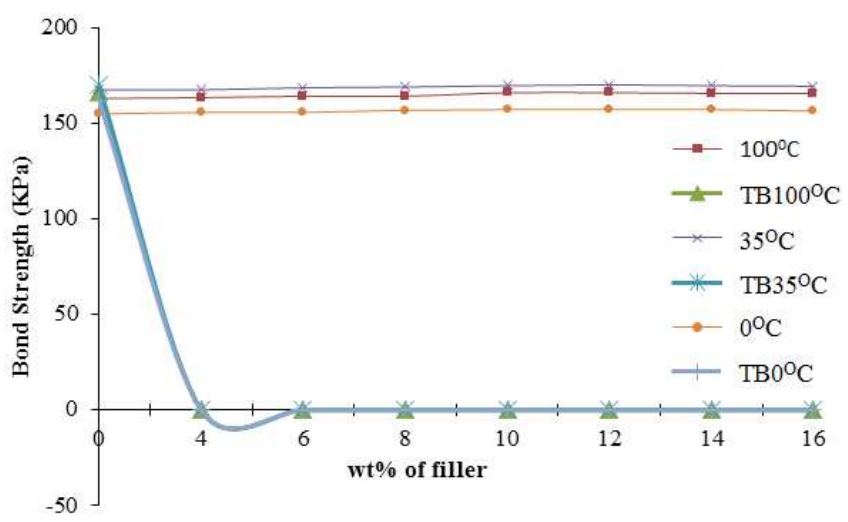

Fig. 2b. Plots of bond strength (KPa) versus wt\% of filler for RHA filled Acrylics/PVA/NR.

adhesives at room temp $\left(35^{\circ} \mathrm{C}\right), 100^{\circ} \mathrm{C}$ and $0^{\circ} \mathrm{C}$

\subsection{Discussion}

\subsection{1. $\mathrm{pH}$}

Table 4 shows the $\mathrm{pH}$ values of $\mathrm{CaCO}_{3}$ or $\mathrm{RHA}$ filled acrylics/PVA/NR wood adhesives. The $\mathrm{pH}$ of pure acrylics/PVA/NR sample was 6.7 but the addition of $14 \% \mathrm{w} / \mathrm{w}$ filler, changed the $\mathrm{pH}$ of acrylics/PVA/NR-CaCO $\mathrm{CO}_{3}$ sample to 6.8 while that of acrylics/PVA/NR-RHA changed to 6.8 when the filler was increased to $16 \% \mathrm{w} / \mathrm{w}$. In all, RHA filled samples were found to maintain more stable $\mathrm{pH}$ than the $\mathrm{CaCO}_{3}$ filled samples. These findings were not unconnected with the $\mathrm{pH}$ difference of the filler materials.

\subsubsection{Bond Strength of Wood Adhesive}

It is evident from Table 5 and Fig. 1a, that after 2 hours of application, both acrylics/PVA/NR- $\mathrm{CaCO}_{3}$ acrylics/PVA/NRRHA have the same bond strength at $4 \mathrm{wt} \%$ filler level. However, there was difference in bond strength in favour of acrylics/PVA/NR-RHA at filler levels of $6 \mathrm{wt} \%$ and above. The same trend of bond strength difference was observed after 24 hours and 7 days of application. The reverse was the case after 24 hours and 7 days of application. It can also be observed that the longer the time after application, the wider the difference in bond strength between acrylics/PVA/NR$\mathrm{CaCO}_{3}$ and acrylics/PVA/NR-RHA. The set-to-touch time [28] of acrylics/PVA/NR-RHA was shorter than that of acrylics/PVA/NR- $\mathrm{CaCO}_{3}$. It may be expected that acrylics/PVA/NR-RHA should coalesce faster, as expressed by Ogban (2007), thereby limiting its flow into the wood pores. But the reverse was observed. This can be explained by the fact that the plasticizing effect of toluene (the NR solvent) and even the flexibilizing effect of rubber itself helped the adhesive to penetrate deep into the wood pores. Deeper penetration of the adhesive into the wood pores is responsible for stronger interlock between adherends. This was thought to be the reason behind the trend of higher bond strength of acrylics/PVA/NR-RHA over acrylics/PVA/NR$\mathrm{CaCO}_{3}$.

Again, the pozzolanic (cementitious) property of RHA which gives synergy to the binding property of the binding agents was observed to increase with time. This was responsible for the observed reversal of increase in bond strength from acrylics/PVA/NR- $\mathrm{CaCO}_{3}$ to acrylics/PVA/NRRHA with RHA showing superior performance to $\mathrm{CaCO}_{3}$. Compared to $\mathrm{CaCO}_{3}$ filler, RHA has lower specific gravity and higher surface area/volume ratio. The greater number of particles per unit volume of RHA in adhesive reduces void spaces in the adhesive thereby increasing the number of bonds per unit volume which was reflected in increase in bond strength.

\subsubsection{Thermal Stability}

The ability of an adhesive to maintain high bond strength even across wide variations of temperature is important. This is because the bonded wood, during use, will definitely be exposed to fluctuation in environmental conditions which may affect the coefficient of thermal expansion of the adherends as well as the adhesive [19]. Table 6 and Fig. 2a and Fig. 2b, show the response of bond strength of the prepared adhesive samples to temperature when the bonded pair was subjected to $100^{\circ} \mathrm{c}$ and $0^{\circ} \mathrm{C}$ temperature for 4 hours. The thermal stability of the adhesives was determined by evaluating the difference in bond strength at room temperature and at lower and higher temperatures.

In comparison, both acrylics/PVA/NR- $\mathrm{CaCO}_{3}$ and acrylics/PVA/NR-RHA adhesives were found to maintain 
more stable bond strength at higher temperature than at lower temperature (Table 6, Fig 2a and Fig 2b). However, on both sides of the temperature difference, acrylics/PVA/NR-RHA adhesive recorded lower difference in bond strength. This established the fact that acrylics/PVA/NR-RHA has higher thermal stability than acrylics/PVA/NR- $\mathrm{CaCO}_{3}$.

\subsection{Conclusion}

In conclusion, the applicability of RHA as filler in adhesives has been established. RHA has lower specific gravity than $\mathrm{CaCO}_{3}$ hence there will be a greater number of RHA particles dispersed in the adhesive which results in higher viscosity of RHA-filled adhesives. The pozzolanic (cementitious) property of RHA has synergistic effect on the binding property of the binding agents thus acrylics/PVA/NR-RHA adhesive has higher bond strength and thermal stability than the $\mathrm{CaCO}_{3}$-filled samples. Comparison of the physical properties of both RHA and $\mathrm{CaCO}_{3}$-filled adhesives with Top Bond reveals that RHAfilled adhesives have values more comparable to Top Bond than the $\mathrm{CaCO}_{3}$-filled samples. Above all, maximum contribution to bond strength was achieved by incorporating between $8 \mathrm{wt} \%$ and $12 \mathrm{wt} \%$ RHA. Beyond $12 \mathrm{wt} \%$ filler level, the bond strength declines for both RHA and $\mathrm{CaCO}_{3}$.

\section{References}

[1] Ulmann's, Encyclopedia of Industrial Chemistry. ed 5. vol A1.VCH Varlagsgese Publishers, Canada (1985), 222-223.

[2] Allen K W, Encyclopedia of Physical Science and Tech. ed 3. Texas A and M University College Station, Texas, USA (2004), $237-250$

[3] Licari James J., and Dale, W. S., Ad. Tech. For Electronic Applications. ed2. Elsevier Applied Science Pub (2011), 35-74

[4] Shukla, R.K. and Mencinger, N.P., A Critical Eeview of VLSI Die Attachment in High Reliability Applications. Solid State Technol (1985), 67 - 74

[5] Siriwardena, S., Ismail, H., Ishiaku, U. S. and Perera, M. C. S., Mechanical and Morphological Properties of White Rice Husk Ash Filled Polypropylene/ethylene-propylene-diene Terpolymer Thermoplastic Elastomer Composites. J. Appl. Polym. Sci. (2002) Vol. 85, 438-453.

[6] Ismail, H., Rozman H.D., Jafri R.M. and Mohd Ishiaku, Z.A., Oil Palm Wood Flour Reinforced Epoxidized Natural Rubber Composites: The Effect of Filler Content and size. Eur.Polm.J. (1997) vol 33, 1627 - 1632

[7] Jayamol, G., Bhagawan, S.S. and Sabu, T., Effect of environment on the Properties of Low Density Polyethylene Composite Reinforced with Pinapple-leaf Fibre. Composite Science and Technology. (1998) vol. 58, 1471 -1485.

[8] Singh, B., Gupta, M. and Verma, A., The Durability of Jute Fibre-reinforced Phenolic Composites. Comp. Sci. and Tech. (2000) Vol. 60, $581-589$.

[9] Seena, J.,Sreekala, M.S., Oomen, Z., Koshy, P. and Sabu, T., Comparison of the Mechanical Properties of Phenol- formaldehyde Composites Reinforced with Banana Fibres and Glass Fibres. Composites Science and Technology, (2002) vol.62, $1857-1868$.

[10] Eric, S., Samd, G. and Lionel, C., Model Development for the description of Silica Particles Dispersion in Silicon Polymer. Chemical Engineering Science, (2006) vol. 6, 5664 - 5677.

[11] Aiping, Z., Aiyum, C., Ziyi, Y. and Weidong, Z., Film Characterization of Poly(styrene-butylacrylate acrylic acid)silica Nanocomposite. Journal of Colloidal and Interface Science. (2008) Vol. 322, 51 - 48

[12] Ji, G., Zhu, H., Jiang, X., Qi, C. and Zhang, X-M, Mechanical strength of Epoxy Resin Composites Reinforced by Calcined Pearl Shell Powders. J. Appl. Polym. Sci. (2009) vol. 114, 3168-3176.

[13] Khan, I. and Poh, B.T., Effect of Silica on Viscosity, Tack, and Shear Strength of Epoxidized Natural Rubber-based PSA in The Presence of Coumarone-indene Resin. J. Appl. Polym. Sci. (2010) vol. 118, 3439 - 3444.

[14] Ramazan K. and Mamdouh, A., Moisture Diffusion into Aluminium Powder-filled Epoxy Adhesive in Sodium Chloride Solution. Int. J. Adhesion and Adhesives 25 (2005), $337-341$.

[15] Igwebike-Ossi, C. D., Application of Rice Husk Ash as new extender in textured paint. J.Chem.Society of Nig., (2012)a vol. $37(1), 72-75$.

[16] Ismail, H., Ishiaku, U.S., Arinab, A. R., and Mohd Ishiaku, Z.A., Effect of Rice Husk Ash Filler on the Mechanical Properties of Natural Rubber Vulcanizate. Int. J. Polm Mater, ed (1997) 36, Pp 39-51.

[17] da Costa, H. M., Visconte, L. L. Y., Nunes, R. C. R. and Furtado, C. R. G., Mechanical and dynamic mechanical properties of rice husk ash-filled natural rubber compounds. $J$. Appl. Polym. Sci., (2002) vol. 83, 2331-2346.

[18] Sae-Oui, P., Rakdee, C. and Thanmathorn, P., Use of Rice Husk Ash as Filler in Natural Rubber Vulcanizates: In comparison with Other Commercial Fillers. J. Appl. Polym. Sci. (2002) Vol. 83, 2485 - 2493.

[19] Fuad, M. Y. A., Mustafah, J., Mansor, M. S., Ishak, Z. A. M. and Omar, A. K.M., Thermal properties of polypropylene/rice husk ash composites. Polym. Int., (1995) vol. 38, 3343.

[20] Toro,P.,Quijada, R., Murillo, O., Yazdani-Pedran, M., Study of the Mophology and Mechanical Properties of Polypropylene Composite With Silica or Rice Husk Ash. Polm. Int., (2005) vol. $54,730-734$.

[21] Stefani, P. M., Cyras, V., Tejeira, A. and Vazquez, A. Mechanical Properties and Thermal Stability of Rice Husk Ash filled epoxy foams. J.App.Polym. Sci. (2006) 99: 2957 2965.

[22] Proctor A, Tan L. C. and Palamappan S., Phospholipid Adsorption onto Rice Husk Ash from Soya Oil Micellas. $J$ Am Oil Chem Soci. (1992) ed. 69, 1049-1050.

[23] Shazim, A. M., Muhammad, A. S. and Hassan, A., Utilization of Rice Husk Ash as Viscosity Mdifying Agent in Self Compacting Concrete. Construction and Building Materials, (2011) ed 25, 1044 - 1048. 
[24] Igwebike-Ossi, C. D., Application of Rice Husk Ash as flatting agent in red oxide primer. J. Chem. Society of Nig. (2012)b vol. 37 (2), 59 - 64.

[25] Igwebike-Ossi, C. D., Rice Rush Ash as flatting extender in cellulose matt paint. American J. appl. Chem. (2014) vol. 2 (6), $122-127$

[26] Ochigbo, S., Roheem F. and Ajai A., Formulations of Waterborne Adhesives Based on Ternary Blends of Latexes. Continental J. Applied Sciences (2011) vol. 6(1), 63-70.
[27] Petrick, R. A., Bond Inspection in Composite Strucyures, Comprehensive Materials (2003) vol 6, 359 - 392

[28] Ogban I. U., The Synergistic Effect of A Commercial Filler with Cellulosic and Crustacean Shells on the Adhesive Properties of Poly(vinyl acetate) Emulsion. Ph.D Thesis, Industrial Chemistry Department, EBSU, Abakaliki, (2007),78-112. 